\title{
Epidural electrical stimulation test versus local anesthetic test dose for thoracic epidural catheter placement: a prospective observational study
}

\section{Test de stimulation électrique péridurale contre test dose d'anesthésie locale pour la vérification du positionnement d'un cathéter péridural thoracique: étude observationnelle prospective}

\author{
Mrinalini Balki, MBBS, MD • Archana Malavade, FCPS Anesthesia $\cdot$ Xiang Y. Ye, MSc • \\ Umamaheswary Tharmaratnam, MD, FRCP
}

Received: 23 April 2018/Revised: 24 October 2018/Accepted: 21 November 2018/Published online: 6 February 2019

(C) Canadian Anesthesiologists' Society 2019

\begin{abstract}
Purpose This study examined the concordance between epidural electrical stimulation test (EEST) and local anesthetic (LA) test dose to indicate correct thoracic epidural catheter position. The relationship between the test results and epidural postoperative analgesia was also assessed.

Methods This prospective observational cohort study was done in patients receiving thoracic epidural analgesia for abdominal surgery. After insertion, the epidural catheter was tested using a nerve stimulator to elicit a motor response. The LA test dose was then administered, and sensory block to ice and pinprick was assessed. The primary outcome was the presencelabsence of motor response to EEST and sensory block to test dose. Concordance of responses was assessed using kappa statistics, and their predictive power of postoperative epidural analgesia was evaluated.
\end{abstract}

This article is accompanied by an editorial. Please see Can J Anesth 2019: this issue.
M. Balki, MBBS, MD ( $\bowtie)$

Department of Anesthesia and Pain Management, Mount Sinai

Hospital, University of Toronto, 600 University Avenue,

Toronto, ON M5G 1X5, Canada

e-mail: Mrinalini.balki@uhn.ca

Department of Obstetrics and Gynaecology, Mount Sinai Hospital, University of Toronto, Toronto, ON, Canada

Lunenfeld-Tanenbaum Research Institute, Sinai Health System, Toronto, ON, Canada
Results Sixty-eight thoracic epidural catheters were inserted, of which 62 were used perioperatively. The kappa agreement between EEST and LA test dose responses was moderate at 0.42 (95\% confidence interval [CI], 0.18 to 0.67). Positive responses to EEST and LA test dose were observed in $62(100 \%)$ and $50(81 \%)$ patients, respectively, while 52 patients (84\%) showed adequate analgesia postoperatively. The sensitivity (95\% CI) of EEST and LA test dose to predict adequate postoperative epidural analgesia was 1 (0.93 to 1) and 0.79 (0.65 to 0.89), respectively, and the positive predictive values $(95 \%$ CI) of EEST and LA test dose were 0.84 (0.75 to 0.93) and 0.82 (0.71 to 0.92), respectively.

Conclusion Following thoracic epidural catheter insertion, the responses to the EEST and LA test dose showed "moderate" agreement. The EEST has a higher sensitivity than the LA test dose to predict adequate epidural analgesia following abdominal surgery, however, both tests have a comparable positive predictive value.

A. Malavade, FCPS Anesthesia - U. Tharmaratnam, MD, FRCP Department of Anesthesia and Pain Management, Mount Sinai Hospital, University of Toronto, 600 University Avenue, Toronto, ON M5G 1X5, Canada

X. Y. Ye, MSc

Micare Research Centre, Mount Sinai Hospital, University of Toronto, Toronto, ON, Canada 


\section{Résumé}

Objectif Cette étude a porté sur la concordance entre le test de stimulation électrique péridurale (EEST) et le test par une dose d'anesthésique local ( $A L)$ pour indiquer la position adéquate d'un cathéter thoracique. La relation entre les résultats des tests et l'analgésie péridurale postopératoire a également été évaluée.

Méthodes Cette étude de cohorte observationnelle prospective a été menée chez des patients recevant une analgésie péridurale thoracique pour chirurgie abdominale. Après insertion, le cathéter épidural a été testé au moyen d'un stimulateur nerveux pour déclencher une réponse motrice. La dose test d'AL a alors été administrée et le blocage sensitif à la glace et aux piqûres a été évalué. Le critère d'évaluation principal était la présence ou l'absence de réponse motrice à l'EEST et au blocage sensitif à la dose test. La concordance des réponses a été évaluée au moyen de statistiques kappa et leur prédiction de l'efficacité de l'analgésie péridurale postopératoire a été évaluée.

Résultats Soixante-huit cathéters périduraux thoraciques ont été insérés parmi lesquels 62 ont été utilisés en périopératoire. La concordance kappa entre les réponses à l'EEST et à la dose test d'AL a été modérée : 0,42 (intervalle de confiance [IC] à $95 \%, 0,18$ à 0,67). Les réponses positives à l'EEST et à la dose test d'AL ont été observées chez respectivement $62(100 \%)$ et $50(81 \%)$ patients, tandis que 52 patients ( $84 \%)$ ont présenté une analgésie postopératoire adéquate. La sensibilité (IC à $95 \%$ ) de l'EEST et de la dose test d'AL pour la prédiction de l'analgésie péridurale postopératoire a été, respectivement, de 1 (0,93 à 1$)$ et 0,79 $(0,65$ à 0,89$)$ et les valeurs prédictives positives (IC à $95 \%)$ de l'EEST et de la dose test d'AL ont été, respectivement, de 0,84 $(0,75$ à 0,93$)$ et $0,82(0,71$ à 0,92$)$.

Conclusion Après insertion d'un cathéter péridural thoracique, la concordance entre l'EEST et la dose test d'AL s'est avérée "modérée ». La sensibilité de l'EEST pour la prédiction d'une analgésie péridurale adéquate après chirurgie abdominale est supérieure à celle de la dose test d'AL; toutefois les deux tests ont des valeurs prédictives positives comparables.

Thoracic epidural analgesia reduces postoperative pain after major thoraco-abdominal surgery. ${ }^{1}$ Additional advantages include decreased pulmonary complications, postoperative ileus, decreased stress response, and enhanced mobility. ${ }^{1-3}$ These advantages have encouraged the incorporation of perioperative epidural analgesia into enhanced recovery after surgery (ERAS) pathways for patients undergoing major thoraco-abdominal surgery. ${ }^{2}$ Nevertheless, despite the well-founded enthusiasm for epidurals, the failure rate of thoracic epidural catheters to provide adequate postoperative analgesia has been reported to be as high as $32 \% .^{4}$ Epidural failure has been attributed to a variety of factors including the incorrect siting of the catheter during its insertion. ${ }^{4}$ The injection of a local anesthetic (LA) "test dose" $-3 \mathrm{~mL}$ of $2 \%$ lidocaine (with or without epinephrine) - through the epidural catheter and subsequent sensory testing is a standard method to help ascertain correct placement of the catheter in the epidural space. ${ }^{5}$ Nevertheless, this test may not be reliable, ${ }^{6,7}$ and other methods have been explored, including the epidural electrical stimulation test (EEST) ${ }^{8}$ epidural pressure waveform analysis, ${ }^{9,10}$ magnetic resonance imaging, ${ }^{11}$ and epidurogram. ${ }^{12}$ Of these, in our opinion, the EEST remains the most promising bedside technique to confirm the correct placement of an epidural catheter.

With the EEST, low-amplitude electrical current is applied to the epidural catheter following its insertion and evoked muscle contraction is sought. While this technique has been studied in various patient populations with excellent results, ${ }^{13-17}$ it remains relatively unfamiliar to most anesthesia health care providers. Moreover, none of the previous studies compared EEST with the LA test dose to assess the correct thoracic epidural catheter position.

The main objective of our study was to determine the concordance between EEST and LA test dose for indicating correct thoracic epidural catheter position. The secondary objective was to compare the ability of both tests to predict adequate postoperative epidural analgesia.

\section{Methods}

Ethical approval for this study (number 13-0079-A) was provided by the Research Ethics Board at Mount Sinai Hospital, Toronto, Ontario, Canada on July 4, 2013. The study was conducted as a prospective observational cohort study at Mount Sinai Hospital from July 2013 to April 2016. Patients undergoing major elective abdominal surgery were approached for participation in the study. Inclusion criteria included patients $>18 \mathrm{yr}$ of age who agreed to epidural analgesia and could communicate in English. They were excluded if they had any contraindication for neuraxial anesthesia/analgesia, abnormal vertebral anatomy (including scoliosis and prior spinal surgery), coexisting neurologic conditions, implanted electronic devices, or had been taking any preoperative sedatives or opioids. Written informed consent was obtained from all patients participating in the study. We adhered to the STROBE (STrengthening the Reporting of OBservational studies in Epidemiology) statement while reporting our findings.

After obtaining baseline vital signs, the epidural catheter was inserted by the attending anesthesiologist or trainee in the mid-low thoracic segments with the patient in the 
sitting position. Using aseptic precautions and following local infiltration with $2 \%$ lidocaine, the epidural space was identified with a loss-of-resistance technique (air or saline) using a $17 \mathrm{G}$ Tuohy needle (midline or paramedian approach). A 19G epidural catheter (Arrow FlexTip Plus, Arrow International Inc., Reading, PA, USA) was inserted and advanced $5 \mathrm{~cm}$ into the epidural space. Negative catheter aspiration was verified to help rule out tip insertion into the intrathecal space or a blood vessel. The catheter was subsequently secured in place using a transparent dressing.

After epidural catheter insertion, EEST was performed using a nerve stimulator (Stimpod NMS450; Xavant Technology (Pty) Ltd; Pretoria, South Africa). ${ }^{18}$ The cathode of the nerve stimulator was attached to the metal hub of a Johans adapter (Arrow-Johans TM ECG adaptor, Arrow International Inc; Reading, PA, USA) placed between the epidural catheter connector and the filter, while the anode was connected to an electrocardiogram electrode placed on the patient's thigh. The catheter was primed with $5 \mathrm{~mL}$ sterile normal saline prior to testing. The nerve stimulator was set at a frequency of $2 \mathrm{~Hz}$ with a pulse width of $0.1 \mathrm{msec}$. The current was gradually increased from $0 \mathrm{~mA}$ to a maximum of $20 \mathrm{~mA}$, until a motor response was elicited either unilaterally or bilaterally in the abdominal region. ${ }^{18,19}$ The current strength $(\mathrm{mA})$ that initiated the motor response was noted. A "test dose" of $2 \%$ isobaric lidocaine $3 \mathrm{~mL}$ was then administered via the epidural catheter and the patient's sensation to ice and pinprick applied bilaterally from the L1 to $\mathrm{T} 2$ dermatomes was assessed five to ten minutes later. ${ }^{5}$ If there was no response to EEST and no sensory block to the LA test dose, the epidural catheter was considered to be incorrectly sited and was removed. The epidural procedure was then repeated or aborted as per the discretion of the attending anesthesiologist. On the other hand, if the EEST and/or LA test dose showed a positive response, the epidural catheter was considered to be correctly positioned in the epidural space and was subsequently used for intra- and postoperative analgesia.

All surgical procedures were performed under general anesthesia with the use of neuromuscular blockers and inhalational agents. Fentanyl $2-3 \mu \mathrm{g} \cdot \mathrm{kg}^{-1}$ was used at induction to reduce the sympathetic response to intubation. Intraoperative analgesia was provided with a continuous epidural infusion of bupivacaine $0.2 \%$ with epimorph 25 $\mu \mathrm{g} \cdot \mathrm{mL}^{-1}$. The infusion was started before the skin incision and the rate of epidural was titrated (4 to $7 \mathrm{~mL} \cdot \mathrm{hr}^{-1}$ ) to maintain systolic blood pressure within $20 \%$ of baseline. During surgery, the epidural was considered to be functioning if no additional narcotics were required to abolish the sympathetic response to surgery. In the event that the epidural was deemed non-functioning as evidenced by clinical signs and monitored parameters,${ }^{20}$ longer-acting opioids such as morphine or hydromorphone were administered intravenously.

Postoperatively, pain score (verbal rating scale [VRS] 0$10,0=$ no pain, $10=$ worst pain) and dermatome level of sensory block to ice were assessed in the recovery area. If the patient complained of pain, a bolus of $5-10 \mathrm{~mL}$ bupivacaine $0.25 \%$ was administered via the epidural catheter. Assessment was done every $30 \mathrm{~min}$ for up to two hours. If the patients remained intubated and/or excessively sedated, this assessment was postponed until adequate recovery of cognitive function. Postoperative analgesia was achieved with patient controlled epidural analgesia (PCEA) using bupivacaine $0.1-0.2 \%$ with morphine $25 \mu \mathrm{g} \cdot \mathrm{mL}^{-1}$ at a rate of 5-7 $\mathrm{mL} \cdot \mathrm{hr}^{-1}$ (bolus $3 \mathrm{~mL}$, lockout $20 \mathrm{~min}$, maximum dose $50 \mathrm{~mL}$ over four hours). The PCEA was usually initiated within $30 \mathrm{~min}$ of admission to the recovery room.

The primary outcome of the study was the presence of a motor response (muscle contraction) to EEST and sensory block to the LA test dose. We assessed the agreement between these two as indications of correct catheter location. The secondary outcomes were postoperative pain score and level of sensory block, as indicators of epidural function. We determined their association with test responses (EEST, LA test dose) to confirm correct epidural catheter position. Postoperative epidural analgesia was considered to be adequate if the VRS pain score was $\leq$ 3 in the presence of a bilateral sensory block. Epidural analgesia was considered to be inadequate if the VRS pain score was $>3$ with either no sensory block or unilateral or patchy block, despite giving additional LA boluses in the recovery area. Data concerning patient demographics, number of epidural insertion attempts, epidural performer, current required for eliciting motor response to EEST, unilateral/bilateral muscle contraction pattern, sensory block to LA test dose, perioperative opioid administration, surgical procedure and duration, and anesthetic management were recorded. All data were collected by a study investigator or research assistant not involved in patient care.

Sample size estimation and statistical analysis

Based on our experience and literature review, the success rate of thoracic epidural catheters in providing adequate perioperative analgesia is estimated to be $75 \%$ following a positive response to the LA test dose. ${ }^{21}$ It is anticipated that the kappa for capturing the degree of the agreement between the EEST and LA test dose response would be 0.8 . A sample size of 57 patients was considered sufficient for the lower bound of its $95 \%$ confidence interval (CI) to be no less than 0.6 , assuming the outcome prevalence of $75 \%$. 
The $\mathrm{R}$ package 'kappaSize' based on the Donner and Rotondi method ${ }^{22}$ was used for the sample size estimation. We decided to recruit $10 \%$ more patients to account for dropout or protocol violations.

The study population was assessed using descriptive statistical methods. The kappa statistic was estimated to determine the degree of agreement between the responses of the EEST and LA test dose. The strength of agreement was defined by the value of kappa: "poor" $<0.20$, "slight" 0.21-0.40, "moderate" 0.41-0.60, "substantial" 0.61-0.80, and "almost perfect" $0.81-1.00 .^{23}$ The sensitivity and specificity, and the positive and negative predictive values of the EEST and LA test dose in predicting epidural function were assessed. Their 95\% CI's were estimated using Clopper-Pearson methodology. ${ }^{24}$ Data were analyzed using SAS version 9.1.3 (SAS Institute, Cary NC, USA) and R 3.4.3 (www.r-project.org).

\section{Results}

Seventy-two patients undergoing abdominal surgical procedures were recruited, of which 64 received the study intervention. A total of 68 epidural procedures were performed in 64 patients, and each procedure was considered as a separate entity. In cases where both EEST and LA test dose responses were negative, epidural catheters were considered to be incorrectly positioned and were removed. The epidural procedure was either repeated $(n=4)$ or aborted $(n=2)$. Epidural analgesia was continued for intra- and postoperative use in 62 cases. The flowchart of patient recruitment is shown in the Figure.

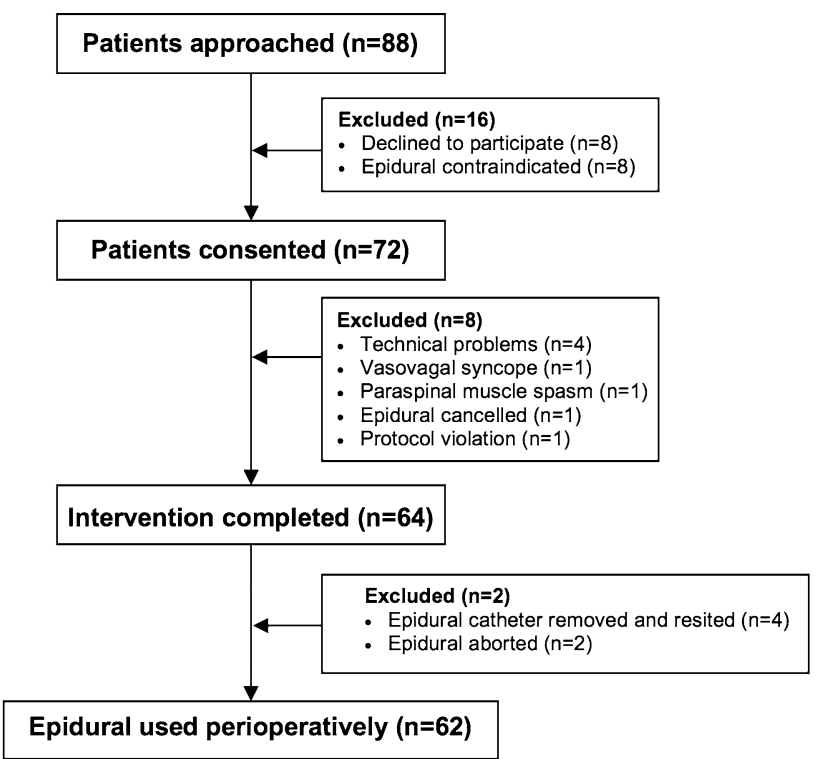

Figure Flow chart of patient recruitment
Patient characteristics and procedure details

The characteristics of patients are shown in Table 1. The mean (standard deviation) age and body mass index of patients were 50 (13) $\mathrm{yr}$ and 27.7 (7.5) $\mathrm{kg} \cdot \mathrm{m}^{-2}$, respectively. Patients underwent gastrointestinal, genitourinary, or retroperitoneal surgical procedures. The spinal segment level of epidural catheter insertion ranged from T6 to T11. Sixty percent of epidural insertions were performed by staff anesthesiologists, while the remaining $40 \%$ were done by clinical fellows or senior residents.

\section{Agreement between EEST and LA test dose}

Of 68 epidural insertion procedures, 62 (91.2\%) and 50 (73.5\%) cases showed a positive response to EEST and LA test dose, respectively. The proportion of agreement was 0.82 (95\% CI, 0.71 to 0.91 ) and Kappa was 0.42 (95\% CI, 0.18 to 0.67 ), thus defining a "moderate" agreement (Table 2). Of the 62 patients with epidural catheters that were used perioperatively, all had a positive motor response to the EEST, while $50(81 \%)$ had a sensory block to the LA test dose.

Postoperative epidural analgesia

Postoperative epidural analgesia was observed in 58 (94\%) patients (Table 3). The epidural did not appear to be working postoperatively in four cases although they were considered to have been functioning intraoperatively (see

Table 1 Patient characteristics and details of thoracic epidural catheter insertion

\begin{tabular}{lc}
\hline Parameters & $n=62$ \\
\hline Age $(\mathrm{yr})$ & $50(13)$ \\
Weight $(\mathrm{kg})$ & $78.9(23.6)$ \\
Height $(\mathrm{cm})$ & $167.3(10.6)$ \\
Body mass index $\left(\mathrm{kg} \cdot \mathrm{m}^{-2}\right)$ & $27.7(7.5)$ \\
Males/females & $25 / 37(40 \% / 59 \%)$ \\
Paramedian/midline approach & $42 / 20(68 \% / 32 \%)$ \\
Ultrasound guidance & $16(26 \%)$ \\
Number of attempts & $2(1 \mathrm{to} 3)$ \\
Epidural depth (cm) & $5.4(1.4)$ \\
Catheter depth (cm) & $10.5(1.8)$ \\
EEST baseline current $(\mathrm{mA})$ & $6.6(3.9)$ \\
Response to EEST, bilateral/unilateral & $25 / 37(40 \% / 60 \%)$ \\
Response to LA test dose, bilateral/unilateral & $46 / 4(74 \% / 6 \%)$ \\
Length of surgery (hr.min $\left.{ }^{-1}\right)$ & $7: 25(4: 0)$ \\
\hline
\end{tabular}

Values expressed as mean (standard deviation), median [interquartile range], or $n(\%)$

EEST $=$ epidural electrical stimulation test LA = local anesthetic 
Methods). One of these patients remained intubated and ventilated in the intensive care unit for two days, hence the epidural catheter could not be tested. Nevertheless, considering this patient's postoperative need for parenteral opioids, the epidural was considered to be non-functional. In another patient, subsequent catheter migration was suspected as the length of the catheter measured at the skin surface changed from $11 \mathrm{~cm}$ (at insertion) to $3 \mathrm{~cm}$ (postoperatively). In the remaining two patients, the cause of epidural failure could not be determined.

Postoperative epidural analgesia was judged to be inadequate in six patients, two of whom had a patchy sensory block, while four had a unilateral block. None of the patients with unilateral or patchy sensory block had received any long-acting opioids intraoperatively, and all had positive responses to both EEST and LA test dose after epidural catheter insertion.

\section{Predictive power}

We removed the epidural catheter when both EEST and LA test dose responses were negative, because we considered that this indicated incorrect catheter placement. As such we could not relate these negative responses to epidural function. Furthermore, there were relatively few patients

Table 2 Agreement between response to EEST and LA test dose

\begin{tabular}{lccc}
\hline EEST motor response & \multicolumn{4}{l}{ Sensory block to ice or pinprick } \\
\cline { 2 - 4 } & Yes & No & Total \\
\hline Yes & $50(73.5 \%)$ & $12(17.7 \%)$ & $62(91.2 \%)$ \\
No & $0(0 \%)$ & $6(8.8 \%)$ & $6(8.8 \%)$ \\
Total & $50(73.5 \%)$ & $18(26.5 \%)$ & $68(100 \%)$ \\
\hline
\end{tabular}

Kappa $(95 \%$ confidence interval $)=0.42(0.18$ to 0.67$)$

EEST $=$ epidural electrical stimulation test LA $=$ local anesthetic

Table 3 Thoracic epidural functioning and response to EEST and LA test dose

\begin{tabular}{ll}
\hline Response & $n=62$ \\
\hline EEST motor response & $62(100 \%)$ \\
Block to ice or pinprick & $50(81 \%)$ \\
Epidural working postoperatively & $58(93.6 \%)$ \\
Epidural adequately working postoperatively & $52(83.9 \%)$ \\
$\quad$ VRS $\leq 3$ and bilateral block) & \\
Epidural inadequate postoperatively (VRS $>3)$ & $10(16 \%)$ \\
Unilateral block & $4(0.06 \%)$ \\
Patchy block & $2(0.03 \%)$ \\
Not working & $4(0.06 \%)$ \\
\hline
\end{tabular}

EEST = epidural electrical stimulation test; LA = local anesthetic; VRS = verbal rating score for pain with non-functional or inadequate epidurals, and so we assessed the predictive power using sensitivity and positive predictive value (PPV) instead of the composite of sensitivity and specificity, such as area under the receiver operating characteristic curve. The sensitivity $(95 \% \mathrm{CI})$ of EEST [1 (0.93 to 1)] was higher compared with the LA test dose $[0.79(0.65$ to 0.89$)]$ response for predicting a functioning epidural (Table 4). The PPV's (95\% CI) of the EEST [0.84 (0.75 to 0.93)] and LA test dose [0.82 (0.71 to 0.92$)$ ] were similar.

Considering the difficulty in calculating specificity and negative predictive value (NPV) due to removal of catheters that failed the EEST and LA test dose, we additionally calculated the sensitivity, specificity, PPV and NPV for best- and worst-case scenarios for each test (Table 4). Nevertheless, the specificity and NPV should be interpreted cautiously.

\section{Discussion}

Our finding suggests that the responses of EEST and LA test dose are in "moderate" agreement with each other for indicating correct positioning of a thoracic epidural catheter into the epidural space. Nevertheless, the EEST showed a higher sensitivity for predicting adequate postoperative epidural analgesia. Our study is novel as it assesses the agreement between EEST and LA test dose response in patients with thoracic epidural catheters.

The higher sensitivity of the EEST to predict adequate postoperative epidural analgesia may be explained by the objective nature of the evoked motor responses, which are visible to both the health care provider and patient. In contrast, the LA test dose requires the subjective assessment of pain and cold that may be conflated with the persisting perceptions of touch and pressure. Moreover, while the response to the LA test dose $(3 \mathrm{~mL}$ of $2 \%$ lidocaine $[ \pm$ epinephrine] assessed five to ten minutes afterwards) may be adequate to indicate intrathecal or intravascular catheter insertion, it may be inadequate (in terms of dose and/or interval) to adequately assess height of block, unilateral/bilateral effect, etc. ${ }^{25}$

The EEST is especially useful in situations when it is not possible, or desirable, to administer or assess the response to a LA test dose prior to the induction of anesthesia. This may be due to the urgency of the situation, where expeditious surgical treatment is of the essence, or the concern with sympatholysis-associated hypotension that could put the patient at risk and complicate induction of general anesthesia. The high PPV for both tests indicates that positive responses to either test are likely to be true positives. The similar specificity of both EEST and LA test 
dose in the best-case scenario implies that they can equally predict incorrect catheter placement.

De Medicis et al. ${ }^{9}$ compared EEST and epidural pressure waveform analysis to assess the correct position of lumbar and thoracic epidural catheters. They observed no differences, with sensitivities and specificities of $80 \%$ and $100 \%$, respectively, when compared with the clinical response as per the acute pain team's postoperative assessment. Charghi et al. ${ }^{17}$ evaluated the reliability of the EEST for thoracic epidural placement of a single-port, metal coil-reinforced epidural catheter (Teracath) containing a removable stylet, and found the sensitivity and specificity to be $92 \%$ and $83 \%$, respectively, following a LA loading dose. Although these findings are close to what we report, the EEST device differed from the ones we used, and the EEST was not compared with a LA test dose. Moreover, unlike our study, postoperative epidural analgesia with LA was not assessed. Tsui et al., ${ }^{8}$ in a pilot study done about two decades ago, found a higher sensitivity and specificity of EEST (100\% and 92\%, respectively) compared with the standard test dose than when compared with postoperative epidural morphine analgesia (96\% and $77 \%$, respectively) following lumbar epidural catheter placement.

In our study, $100 \%$ of the patients with a positive response to the EEST had adequate intraoperative analgesia, but only $80 \%$ had a positive LA test dose response. The overall epidural failure rate to provide adequate postoperative analgesia was $16 \%$, which falls in the previously reported range $(13-32 \%) .{ }^{4}$ The failure to provide adequate epidural analgesia in our study was attributed to migration or dislodgement of the catheter, and inadequate spread of LA in the epidural space. An underappreciated cause of inadequate blocks relates to the continuous epidural infusion of drugs, which can result in a non-uniform distribution of LA solution compared with pre-programmed intermittent epidural boluses. ${ }^{26}$ While EEST can confirm catheter placement in the epidural space, it may not be able to predict the adequate spread of LA, which can be dependent on several factors including anatomical variation, presence of septa in the epidural space, inadequate dosing, or mismatch between surgical incision and the spinal segment chosen for epidural catheter insertion.

The incidence of unilateral motor response to the EEST $(60 \%)$ was lower than that observed with lumbar epidural catheter testing (71-90\%). ${ }^{14,19}$ Similar to others, ${ }^{14,19}$ we observed that a unilateral motor response to the EEST was not associated with unilateral block postoperatively, except in four patients. Of note, in these four cases, all showed a bilateral sensory block to ice or pinprick after the administration of the LA test dose. It is possible that, even if the catheter tip is closer to one side, the LA solution still distributes circumferentially in the epidural space. Hence, the significance of unilateral $v s$ bilateral motor responses remains unclear, as this does not seem to have an obvious relationship to the spread of the block. Additional factors that have been considered to affect the laterality of the evoked motor response to the EEST include catheter type (uniport $v s$ multiport catheters) ${ }^{27}$ and stimulation pulse width $(0.1 \mathrm{msec} v s 1 \mathrm{msec}),{ }^{28}$ but neither has been shown to be of consequence.

Forster et al. ${ }^{12}$ reported several technical difficulties using the EEST including the frequent need for saline flushing because of electrical circuit interruption, current oscillation, and pain/paresthesia during stimulation. In addition, interpretation of the evoked motor response was complicated by respiratory movements, shivering, tremor, nervousness, and abdominal aortic pulsation. We encountered technical problems related to battery malfunction and electrical circuit interruptions that required saline flush. Moreover, one patient had severe paraspinal muscular spasms during stimulation that precluded further assessment of the EEST. It should also be acknowledged that the EEST demands additional attention to maintenance of a strict aseptic technique. Nevertheless, the majority of our patients tolerated the procedure well without any complications.

As the EEST showed a higher sensitivity compared with the LA test dose for predicting adequate postoperative epidural analgesia, consideration could be given to routinely using it to help assess correct thoracic epidural catheter placement. For the EEST to become widely adopted as the gold standard to assess epidural catheter position, more data are required to show that it should replace the LA test dose. In particular, more information is required to differentiate these tests' ability to predict functioning versus inadequate versus non-functioning epidurals with regard to postoperative analgesia. Moreover, the above-mentioned technical concerns regarding the EEST need to be resolved.

A limitation to this study is that patients were not randomized to either EEST or LA test dose. Nevertheless, this would have precluded using patients as their own controls. Those providing anesthesia care were not blinded to the EEST or LA test dose responses, and so we cannot rule out assessment bias of the test responses. This could be of particular relevance for the LA test dose which, by design, followed the EEST. Nevertheless, those assessing postoperative epidural analgesia were indeed blinded to the test results. In the four patients with negative responses to both the EEST and LA dose test, the epidural catheter was 
Table 4 Predictive power using sensitivity and specificity with $95 \%$ confidence interval

Gold standard: epidural working postoperatively

\begin{tabular}{|c|c|c|c|c|}
\hline$n=62$ & Sensitivity & Specificity & PPV & NPV \\
\hline EEST & $1(0.94$ to 1$)$ & - & $0.94(0.88$ to 1$)$ & - \\
\hline LA test dose & $0.79(0.67$ to 0.89$)$ & - & $0.92(0.77$ to 1$)$ & - \\
\hline \multicolumn{5}{|l|}{$n=68$} \\
\hline EEST (best scenario*) & $1(0.9$ to 1$)$ & $0.60(0.26$ to 0.88$)$ & $0.94(0.88$ to 1$)$ & $1(\mathrm{NA}) * *$ \\
\hline EEST (worst scenario*) & $0.91(0.83$ to 0.98$)$ & $0(\mathrm{NA}) * *$ & $0.94(0.88$ to 1$)$ & $0(\mathrm{NA}) * *$ \\
\hline LA test dose (best scenario*) & $0.79(0.69$ to 0.90$)$ & $0.60(0.26$ to 0.88$)$ & $0.92(0.84$ to 0.99$)$ & $0.33(0.11$ to 0.55$)$ \\
\hline LA test dose (worst scenario*) & $0.72(0.59$ to 0.82$)$ & $0(\mathrm{NA}) * *$ & $0.92(0.84$ to 0.99$)$ & $0(\mathrm{NA}) * *$ \\
\hline \multicolumn{5}{|c|}{ Gold standard: epidural adequately working (bilateral block) postoperatively\$ } \\
\hline$n=62$ & Sensitivity & Specificity & PPV & NPV \\
\hline EEST & $1(0.93$ to 1$)$ & - & $0.84(0.75$ to 0.93$)$ & - \\
\hline LA test dose & $0.79(0.65$ to 0.89$)$ & - & $0.82(0.71$ to 0.92$)$ & - \\
\hline \multicolumn{5}{|l|}{$n=68$} \\
\hline EEST (best scenario*) & $1(0.93$ to 1$)$ & $0.38(0.15$ to 0.65$)$ & $0.84(0.75$ to 0.93$)$ & $1(\mathrm{NA}) * *$ \\
\hline EEST (worst scenario*) & $0.90(0.82$ to 0.97$)$ & $0(\mathrm{NA}) * *$ & $0.84(0.75$ to 0.93$)$ & $0(\mathrm{NA}) * *$ \\
\hline LA test dose (best scenario*) & $0.79(0.65$ to 0.89$)$ & $0.44(0.19$ to 0.68$)$ & $0.82(0.71$ to 0.92$)$ & 0.39 (0.16 to 0.62$)$ \\
\hline LA test dose (worst scenario*) & $0.71(0.59$ to 0.82$)$ & $0.10(0.003$ to 0.45$)$ & $0.82(0.71$ to 0.92$)$ & $0.06(0$ to 0.17$)$ \\
\hline
\end{tabular}

EEST $=$ epidural electrical stimulation test $\mathrm{LA}=$ local anesthetic; $\mathrm{NA}=$ not available; $\mathrm{NPV}=$ negative predictive value PPV $=$ positive predictive value

\$Implies bilateral block and excludes those with patchy, unilateral blocks and non-functional epidurals. Of 68 subjects, six were failures for both EEST and test dose. *We included these six in the analysis assuming (a) all six subjects had non-working/not adequately working epidural (best scenario); (b) all six subjects had working/adequately working epidural (worst scenario). $* *$ The $95 \%$ confidence interval could not be calculated

removed and another was sited. Arguably, the data from these repeat-catheter patients should have been eliminated from further inclusion as we cannot rule out a confounding effect of the initial epidural catheter insertion and testing. With two other patients in whom responses to both tests were negative, epidural catheter insertion was not reattempted. Removal of the epidural catheters in these six patients precluded calculation of the specificity and NPV of the EEST and LA dose test. Further prospective studies are required to test for specificity of thoracic epidural catheters for predicting postoperative analgesia.

In conclusion, following thoracic epidural catheter insertion, responses to the EEST and LA test dose have "moderate" agreement. Nevertheless, since the 95\% CI of the estimate was relatively wide in our study, a larger study or meta-analysis, if applicable, may be warranted. The EEST has a higher sensitivity than the LA test dose to predict adequate epidural analgesia following abdominal surgery while both tests have a comparable PPV. We believe the EEST has the potential to become the gold standard for testing the placement of thoracic epidural catheters.
Acknowledgements We would like to thank Ms. Kristi Downey, Anesthesia Research Coordinator, Mount Sinai Hospital for creating a database for the study and Dr. Devdatta Desai, Anesthesia fellow, Mount Sinai Hospital, for assisting with the initial study planning.

Conflicts of interest The authors have no conflicts of interest.

Editorial responsibility This submission was handled by Dr. Steven Backman, Associate Editor, Canadian Journal of Anesthesia.

Author contributions Mrinalini Balki contributed substantially to all aspects of this manuscript, including study conception and design, acquisition, analysis, and interpretation of data, and drafting the article. Archana Malavade contributed substantially to the acquisition, analysis, and interpretation of data, and revision of the article. Xiang $Y$. Ye contributed substantially to the conception and design, analysis, and interpretation of data, and revision of the article. Uma Tharmaratnam contributed substantially to conception and design; acquisition, analysis, and interpretation of data, and revision of the article.

Funding Mrinalini Balki was supported by Merit awards, Department of Anesthesia, University of Toronto, Canada. This research did not receive any specific grant from funding agencies in the public, commercial, or not-for-profit sectors. 


\section{References}

1. Manion SC, Brennan TJ. Thoracic epidural analgesia and acute pain management. Anesthesiology 2011; 115: 181-8.

2. Weiss $R$, Pöpping DM. Is epidural analgesia still a viable option for enhanced recovery after abdominal surgery. Curr Opin Anaesthesiol 2018; 5: 622-9.

3. Pöpping DM, Elia N, Van Aken HK, et al. Impact of epidural analgesia on mortality and morbidity after surgery: systematic review and meta-analysis of randomized controlled trials. Ann Surg 2014; 259: 1056-67.

4. Hermanides J, Hollmann MW, Stevens MF, Lirk P. Failed epidural: causes and management. Br J Anaesth 2012; 109: 14454.

5. Camorcia M. Testing the epidural catheter. Curr Opin Anesthesiol 2009; 22: 336-40.

6. Palkar NV, Boudreaux RC, Mankad AV. Accidental total spinal block: a complication of an epidural test dose. Can J Anaesth 1992; 39: 1058-60.

7. Crosby E, Halpern $S$. Failure of a lidocaine test dose to identify subdural placement of an epidural catheter. Can J Anaesth 1989; 36: 445-7.

8. Tsui BC, Gupta S, Finucane B. Confirmation of epidural catheter placement using nerve stimulation. Can J Anaesth 1998; 45: 6404.

9. de Medicis E, Tetrault JP, Martin R, Robichaud R, Laroche L. A prospective comparative study of two indirect methods for confirming the localization of an epidural catheter for postoperative analgesia. Anesth Analg 2005; 101: 1830-3.

10. Al-Aamri I, Derzi SH, Moore A, et al. Reliability of pressure waveform analysis to determine correct epidural needle placement in labouring women. Anaesthesia 2017; 72: 840-4.

11. Elsharkawy H, Sonny A, Chin KJ. Localization of epidural space: a review of available technologies. J Anaesthesiol Clin Pharmacol 2017; 33: 16-27.

12. Förster JG, Niemi TT, Salmenperä MT, Ikonen S, Rosenberg PH. An evaluation of the epidural catheter position by epidural nerve stimulation in conjunction with continuous epidural analgesia in adult surgical patients. Anesth Analg 2009; 108: 351-8.

13. Tsui BC, Gupta S, Finucane B. Determination of epidural catheter placement using nerve stimulation in obstetric patients. Reg Anesth Pain Med 1999; 24: 17-23.

14. Margarido CB, Dlacic A, Balki M, Furtado L, Carvalho JC. The epidural electric stimulation test does not predict local anesthetic spread or consumption in labour epidural analgesia. Can J Anesth 2013; 60: 393-8.
15. McAuliffe NA, Pickworth S, Direnna T, Hong A. Electrophysiological stimulation (Tsui test) is feasible for epidural catheter positioning in adults with chronic back pain: a cohort study. Can J Anesth 2013; 60: 976-81.

16. Hayatsu K, Tomita M, Fujihara $H$, et al. The placement of the epidural catheter at the predicted site by electrical stimulation test. Anesth Analg 2001; 93: 1035-9.

17. Charghi $R$, Chan SY, Kardash KJ, Finlayson RJ, Tran DQ. Electrical stimulation of the epidural space using a catheter with a removable stylet. Reg Anesth Pain Med 2007; 32: 152-6.

18. Xavant Technology. Stimpod NMS 450 Features and benefits. Available from URL: http://www.xavant.com/products/nms 450 (accessed November 2018).

19. Tsui BC. Epidural stimulation test criteria. Anesth Analg 2006; 103: 775-6.

20. Stomberg $M W$, Sjöström B, Haljamäe $H$. Assessing pain responses during general anesthesia. AANA J 2001; 69: 218-22.

21. Weitz SR, Drasner K. Local anesthetic test dose as a predictor of effective epidural opioid analgesia. Anesthesiology 1995; 83: 96100.

22. Donner A, Rotondi MA. Sample size requirements for interval estimation of the kappa statistic for interobserver agreement studies with a binary outcome and multiple raters. Int $\mathrm{J}$ Biostat 2010; 6: Article 31.

23. Landis JR, Koch GG. The measurement of observer agreement for categorical data. Biosmetrics 1977; 33: 159-74.

24. Clopper CJ, Pearson ES. The use of confidence or fiducial limits illustrated in the case of the binomial. Biometrika 1934; 26: 404 13.

25. Guay J. The epidural test dose: a review. Anesth Analg 2006; 102: 921-9.

26. Mowat I, Tang R, Vaghadia H, Krebs C, Henderson WR, Sawka $A$. Epidural distribution of dye administered via an epidural catheter in a porcine model. Br J Anaesth 2016; 116: 277-81.

27. Patel R, Arzola C, Petrounevitch V, et al. Response patterns to the electric stimulation of epidural catheters in pregnant women: a randomized controlled trial of uniport versus multiport catheters. Anesth Analg 2016; 123: 950-4.

28. Zakus P, Bittencourt $R$, Downey K, Tsui BC, Carvalho JC. The effect of an increased pulse width on the pattern of motor response (unilateral versus bilateral) during the Tsui test in labouring parturients: a randomized crossover trial. Can J Anesth 2017; 64: 1211-7.

Publisher's Note Springer Nature remains neutral with regard to jurisdictional claims in published maps and institutional affiliations. 